\title{
Introduction: Innovations in interpreting research methods
}

The International Journal for Translation \& Interpreting Research trans-int.org
Raquel de Pedro Ricoy

Heriot-Watt University, UK

R.DePedro@hw.ac.uk

Jemina Napier

Heriot-Watt University, UK

J.Napier@hw.ac.uk

DOI: 10.12807/ti.109201.2017.a01

With an increasing amount of empirical research being conducted in interpreting studies through social science, humanities and interdisciplinary lenses, more interest is being paid to the nature of the research methods being used. This is evidenced by the publication of a monograph focusing solely on interpreting research methods (Hale \& Napier 2013), as well as the inclusion of a dedicated panel (Moving boundaries in translation and interpreting research methods) in the program of the $8^{\text {th }}$ European Society for Translation Studies (EST) Congress (Aarhus, Denmark, 2016), which was convened and facilitated by Napier and de Pedro Ricoy. The recently published Routledge Encyclopedia of Interpreting Studies (Pöchhacker, 2015) has 21 entries referring specifically to interpreting research, including: action research, bibliometric research, corpus-based research, experimental research, mixedmethods research, survey research, ethnographic methods, methodology, eye tracking, retrospective protocols, the activist approach, cognitive approaches, discourse-analytical approaches, linguistic/pragmatic approaches, neuroscience approaches, psycholinguistic approaches, sociolinguistic approaches, sociological approaches, epistemology, interdisciplinarity, and paradigms.

The publication of this special issue is, therefore, timely. It brings together a collection of articles that specifically discuss innovations in interpreting research methods. Its aim is to consider and discuss how research methods have been used in interpreting studies, and how innovation in the application of such methods can move boundaries in understanding the work of both spoken and signed language interpreters. Studies such as these, conducted on the basis of innovative, cross-disciplinary approaches, can have an impact on promoting best practice and influencing policy, thus yielding benefits for communities and society at large.

Collectively, the articles present a critical exploration of how research methods that have been traditionally used in interpreting studies can be adapted to analyze the reality of professional practice in the $21^{\text {st }}$ century. In addition, they also illustrate how the utilization of tools more commonly associated with other disciplines can add further insights into linguistically 
and/or culturally mediated encounters. In showcasing novel applications of well-established methods (quantitative, qualitative or mixed), the articles in this special issue provide an overview of the state of the art in the discipline from both established scholars and early career researchers. Each paper highlights how and why adopting an innovative research method can extend our understanding of the complexities of interpreting and promote a deeper appreciation of the work of interpreters. In considering the range of papers included in this special issue, we can see that each contribution introduces methods as yet under-utilized in interpreting studies, or they explore how previously used methods can be used more innovatively.

Chen adopts a more quantitative approach in the analysis of note-taking in consecutive interpreting through the use of digital-pen technology, which she shows to be a useful method to gain insight into both the interpreting process and the management of the interpreters' cognitive load. The particular innovation in her study is the use of the digital-pen technology for capturing data. Digital pen technology has also been used to investigate how to teach note-taking to interpreting students (Orlando, 2010).

Hokkanen employs an auto-ethnographic approach to exploring her position as an interpreter-researcher-a 'practisearcher' (Gile, 1994) and emotions experienced in interpreting fieldwork. Her emphasis is on this method as a non-traditional approach to processing first-hand research material that can throw light on the complex relationship between the researcher's multiple selves and the relevant social setting.

In her article, de Pedro Ricoy focuses on interviews conducted with Peruvian indigenous community leaders who had participated in an interpreter-mediated consultation process. She evaluates the implications of adapting a well-established method in interpreting studies for the purposes of studying the role of interpreting in a novel socio-political context, thus asking us to consider other innovative ways of drawing upon qualitative interviews in our discipline.

Shamy and de Pedro Ricoy report how they utilized retrospective protocols to explore trainee interpreters' perceptions of language-pair-specific difficulties when working in simultaneous mode. This method is innovative in that the exploration involves the language combination English-Arabic, which has received little scholarly attention, and in that the application of the method makes a contribution to process-oriented research in interpreting pedagogy.

Stone's article draws upon an established methodology rarely used in interpreting studies, namely a longitudinal approach, to measure signed language interpreting student performance on the basis of a battery of tasks. By undertaking this kind of study, he argues that a clearer picture of the students' progression from training through to employment can be gleaned. Stone's article provides us with innovation in two ways: through the design of a longitudinal study (rarely seen in interpreting studies) and also the application of existing instruments used to measure language skills development in other contexts.

Vargas-Urpi reviews critically the benefits of using a multi-method research approach to investigate public service interpreting (PSI). She reports on findings from her own study and suggests that, although it is timeconsuming, a multi-method approach is an effective manner of gaining a holistic overview of the intricacies of PSI. Pöchhacker (2011) has also asserted that using multi- or mixed-methods research design in interpreting 
studies is an effective way to explore the complex nature of interpreting processes and practices.

Finally, Wurm and Napier discuss how community participatory research methods can be used to engage all stakeholders in any interpreting research, including interpreters themselves, service users and service providers. They draw on examples of two previous studies that explored perceptions of signed language interpreting to illustrate how involving participants not only in interviews, but also in other aspects of the research process, can rebalance the power differential in ensuring that research is conducted with rather than on stakeholders. Community participatory research is an established approach in healthcare research, but Wurm and Napier propose that it could be utilized more in interpreting studies.

In sum, our goal in drawing together a collection of articles in one special issue like this, was to highlight the inventive ways that interpreting researchers are extending and enhancing our approaches to conducting research, and opening up our discipline to methods widely used in other disciplines. We hope that readers of this issue will be inspired to consider exploring other innovative methods not featured here.

\section{References}

Gile, D. (1994). Opening up in interpretation studies. In M. Snell-Hornby, F. Pöchhacker \& K. Kaindl (Eds.), Translation Studies: An interdiscipline (pp.149158). Amsterdam: John Benjamins.

Orlando, M. (2010). Digital pen technology and consecutive interpreting: Another dimension in note-taking training and assessment. The Interpreters' Newsletter, 15, 71-86.

Pöchhacker, F. (2011). Researching interpreting: Approaches to inquiry. In B. Nicodemus \& L. Swabey (Eds.), Advances in interpreting research: Inquiry in action (pp.5-25). Amsterdam and Philadelphia: John Benjamins.

Pöchhacker, F. (Ed.) (2015). Routledge encyclopedia of Interpreting Studies. Abingdon and New York: Routledge. 